\title{
Thermodinamics and Mutual Distribution of Macromolecules in the Systems: Chlorine- Chlorocontaining Polymers
}

\author{
Shixaliyev Kerem Sefi
}

\begin{abstract}
In given work a scientific base compatibility of polymers, produced by industry have been studied by revealing of thermodynamically regularities of polymer mixtures.

The most significant thermodynamic regularities of the mixtures of polyolefin , produced by industry and heterochained polymers have been revealed and on this base the scientific bases of their compatibility have been developed for creation of multicomponent compositional materials with given complex of operating properties.

Key words: polymer-polymer mixtures, chlorinated polyethylene (CPE), polymethylmetaacrylate (PMMA), polyethylene of low density (PELD), chlorcarboxylated polyethylene of low density (CCPE) chlorinated PELD (CPE), polyvinyl chloride (PVC), criteria of compatibility, chlorination, upper and lower critical temperature, specific holding of volume, Qibbs mixing energy, parameter of solubility, distribution of macromolecules, chlorine-chlorocontaining polymers, polar groups, thermodynamically compatibility, sorbate, gas-carrier.
\end{abstract}

\section{INTRODUCTION}

Need of industry in new polymer materials, possessing by necessary properties for work in extremal conditions continuously increase. It is may be achieved by synthesis of the new types of polymers and creation of polymer compositions where properties of the separate components additively are the complement of one another [1-5]. Therefore development of different polymer compositions by simplification of technology its production and processing, shortening expenditures on production of materials with necessary complexes of properties is extremely actual. For production of the new types of polymer materials by use of polymer-polymer mixtures determination of its thermodynamically stability as one of the factors, deterring a structure and properties of the final product acquire essential interest [6-8]. Use of chlorcontaining polymers in industry, stipulated by complex of enough good properties determine the desire to improvement of series them indices. From this point of view research of thermodynamical conduct of chlorpolymers mixtures with another chlorpolymers, having in their composition the polar groups of chlorpolymers present a special interest.

\footnotetext{
Manuscript received on 26 March 2021 | Revised Manuscript received on 01 April 2021 | Manuscript Accepted on 15 April 2021 |Manuscript published on 30 April 2021.

Shixaliyev Kerem Seyfi , Doctor of Technical Sciences, ProfessorAcademician of the European Academy of Natural Sciences Professor, Department of Organic Substances and Technology of Macromolecular Compounds Azerbaijan State Oil and Industry University, Baku, Azerbaijan kerem_shixaliyev@mail.ru

(c) The Authors. Published by by Lattice Science Publication (LSP). This is an open access article under the CC-BY-NC-ND license (http://creativecommons.org/licenses/by-nc-nd/4.0/)
}

In the work [9] thethermodynamicallycompatibility of chlorinated polyethylene (CPE) with different chlorination degree, shown that by dominant of dispersion forces compatibility is possible by proximity parameters of solubility and interaction. Analysis of compatible and incompatible pairs shown that:

- $\quad$ by difference in chlorine content, reaching

- $18 \mathrm{mas} \% \Delta \mathrm{H}_{\mathrm{m}}$ is relatively high (+0.519 Joul/g)

Owing to big difference in thermal coefficients expansion - $\mathrm{T} \Delta \mathrm{S}_{\mathrm{m}}$ is positive $(+0.276 \mathrm{Joul} / \mathrm{g})$. The total energy $\Delta \mathrm{G}_{\mathrm{m}}$ is positive $(+0.795 \mathrm{Joul} / \mathrm{g})$. From this it is conduced that a mixture must be inmixing (incompatible);

- by approximately near content of chlorine (27 and 35 mas\%) the dispersion forces between molecule, owing to similarity lead to little interaction degree. By calculation, a big difference in thermal coefficients expansion gives a little negative value $\Delta \mathrm{H}_{\mathrm{m}}(-0.108 \mathrm{Joul} / \mathrm{g})$. But this difference causes a big positive $-\mathrm{T} \Delta \mathrm{S}_{\mathrm{m}}(+0.761 \mathrm{Joul} / \mathrm{g})$ and in result $\Delta \mathrm{G}_{\mathrm{m}}(+0.653 \mathrm{Joul} / \mathrm{g})$ doesn't favoruable to mixing.

\section{METHOD}

It have been determined, that uniting criteria of compatibility $\Delta \mathrm{G}_{\mathrm{m}}<0[7,8]$ in total case is carried out, although a structural compatibility is possible also by little positive values of $\Delta \mathrm{G}_{\mathrm{m}}$. In all cases the surplus energy $\Delta \mathrm{S}_{\mathrm{m}}$ doesn't favorable to mixing, but by proximity of percent content of chlorine and coefficient of thermal expansion the compatibility is possible.

In the work [9] the system (CPE - PMMA) have been studied. It was shown that polymethylmetacrylate (PMMA) is compatible with chlorinated polyethylene by appointed chlorination degree of the last and only by appointed temperatures. It have been determined that a mixtures have an upper and lower critical temperatures of solubility.

The present work devotes to study of thermodynamic interaction between components mixture of chlorocontaining polymers, one of which in its composition have a polar carboxylic groupings. By that the method of turned gas chromatography have been used, which at the last time is widely applied for study of polymers compatibility.

As initial raw materials the industrial samples of polymers: chlorocarboxylated polyethylene of low density PELD (CCPE) with contact of chlorine equal 27 mas \% and carboxylic groups 1.2 mas. \% correspondingly, chlorinated PELD (XPE) with chlorine content 35 mas. \% and polyvinylchloride (PVC) by brand C-70 have been used, the characteristics of which are presented in the table 1

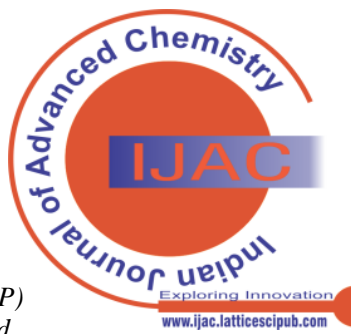


Table1Characteristic of investigated polymers

\begin{tabular}{|c|c|c|c|c|c|c|c|c|c|c|}
\hline 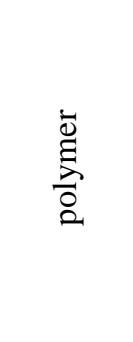 & 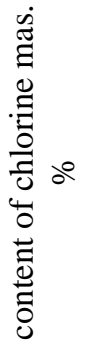 & 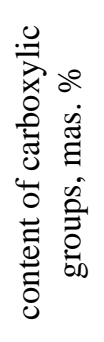 & 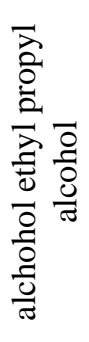 & $\begin{array}{l}\stackrel{0}{\oplus} \\
\ddot{\theta}\end{array}$ & $\frac{+{ }^{+}}{\stackrel{\Sigma}{\Sigma}}$ & $\stackrel{m}{\stackrel{0}{\Sigma}}$ & $\sum_{\Sigma}$ & 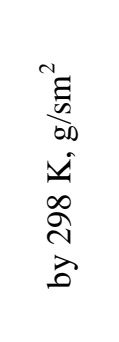 & $\frac{+}{\stackrel{1}{0}}$ & 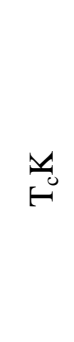 \\
\hline ССРE & 2.7 & 1.2 & - & - & 3.5 & 5.7 & 6.11 & 1.0713 & 8.64 & 239 \\
\hline $\begin{array}{l}\mathrm{CPE} \\
\end{array}$ & 35 & - & - & - & 3.5 & 5.8 & 6.08 & 1.0713 & 5.80 & 263 \\
\hline PVC & 57 & - & - & & 15.0 & 47.0 & 3.19 & 1.3446 & 3.09 & 349 \\
\hline $\begin{array}{l}\text { packing } \\
\text { products }\end{array}$ & - & - & - & 4:3:1 & 3.0 & 10.2 & 2.95 & 1.2284 & 4.63 & 238 \\
\hline SKEP & - & - & 1.0 & - & 9.0 & 30.2 & 2.98 & 0.8723 & 8.59 & 2.11 \\
\hline
\end{tabular}

D:B:0* - 4.4 - diphenylmethanediisosianate; 1.4

butadiol:oligoethylenebutyleneglycoladipinate

For research the chromographycal columns with individual polymers and its mixtures by correlation of components 30:40, 50:50, 70:20 have been prepared/ In the work the chromatograph "Tsvet-100" with flame ionization detector have been used. As a gas-carrier the nitrogen and as sorbate ten solvents, relating to different classes (alcohols, ketons and chloroderivatives of aliphatic hydrocarbons) have been used.

The temperatures of chramotographycal measuring were higher of temperatures $T_{c}$ of investigated polymers and made up for all systems 353, 373 and 393 K. Method measuring is in detail stated in the work [10].

\section{RESULTS}

In all investigated systems dependence of specific holding volume of sorbate $V_{g}^{q}$ from value of sample within 0.01-0.1 mol doesn't observed. In case of dependence $V_{g}^{q}$ from rate of gas-carrier the extrapolation to zero rate of gascarrier have been conducted. Contribution of adsorption effects to value of holding volumes wasn't taken into consideration because content of polymer phase on Teflon carrier was in all cases more than $6.5 \%$.

On base of experimental data by absolute specific holding volumes of sorbates $V_{g}^{0}$ and specific volumes of polymers the parameters interaction of sorbate with every polymer $X_{12}^{\infty}-X_{13}^{\infty}$ and their mixtures $X_{1}^{\infty}(23)$ have been calculated. The parameters interaction $X_{23}^{+}$of polymer with one another have been determined. Calculation have been conducted by equations, offerendby Patterson with collaborators $[11,12]$.

$$
\begin{gathered}
X_{12}^{\infty}=\ln \left[\frac{273.2 \cdot\left(\omega_{2} v_{2}+\omega_{3} v_{3}\right)}{P_{1}^{0} \cdot V_{g}^{0} \cdot V_{1}}\right]-\left(1-\frac{V_{1}}{M_{2} v_{2}}\right)-\frac{P_{1}^{0}}{R T} \\
X_{12}^{\infty}=\ln \left[\frac{\left.273.2 \cdot g_{I} \cdot V_{1}\right)}{P_{1}^{0} \cdot V_{g}^{0} \cdot V_{1}}\right]-\left(1-\frac{V_{1}}{M_{2} v_{2}}\right)-\frac{P_{1}^{0}}{R T} \\
\cdot\left(B_{I I} \cdot V_{1}\right)
\end{gathered}
$$

Where R - is universal gas constant; $v_{2}, v_{3}, V_{2} \cdot V_{3}-$ specific molar volumes of polymers and molecular mass of thermodynamicallysegments; $\omega_{2}, \omega_{3}, Y_{2}, Y_{3}$ - mass. volume parts of polymers; $P_{1}^{0}, V_{1}, B_{I I}$ - pressure of saturated vapour, molar volume and the second variable coefficient of sorbet by temperature $\mathrm{T}$.

As sorbates it is recommended to use solvents, which minimally combine conduct of both polymers, that is close to ideal solvents of both polymers [10].

The received in that case values $X_{1(23)}^{\infty}-X_{23}^{\infty}$ are correct and may be used for valuation of thermodynamical compatibility of polymers [11]. Thus from all spectrum of sorbate by compatibility two TQF and chloroform (CF) have been selected, which for investigated samples of polymers which by temperature of experiment turned out to be the most close to ideal solvents.

On Figure 1 change of the value $X_{1(23)}^{\infty}$ from composition of both systems is presented. As it is evident, in both cases values differ from additive, moreover for system CCPE-CPE value in the all sphere of investigated composition is lower of additive by increase of difference by rise of CCPE content. For system CCPE-PVC by correlation of components 50:50 value of $X_{23}^{\infty}$ coincide with additive, that is in presence of total solvent the thermodynamically interaction between components is getting worse.

The received values have been used for calculation of parameters interaction with one another by equation

$$
=\frac{X_{12}^{\infty} Y_{2}+X_{13}^{\infty} Y_{3}-x_{1(23)}}{Y_{2} Y_{3}}
$$

For both systems in investigate fields concentrations values $X_{23}^{\infty}>0$ and strongly are changed by value with change of composition that indicate on change of conduct of composition mixture.

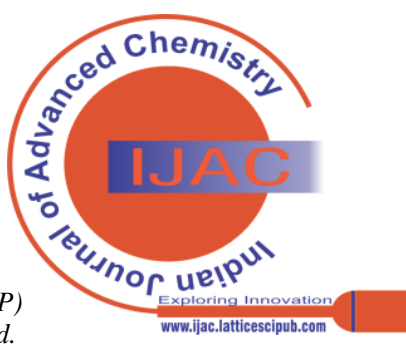



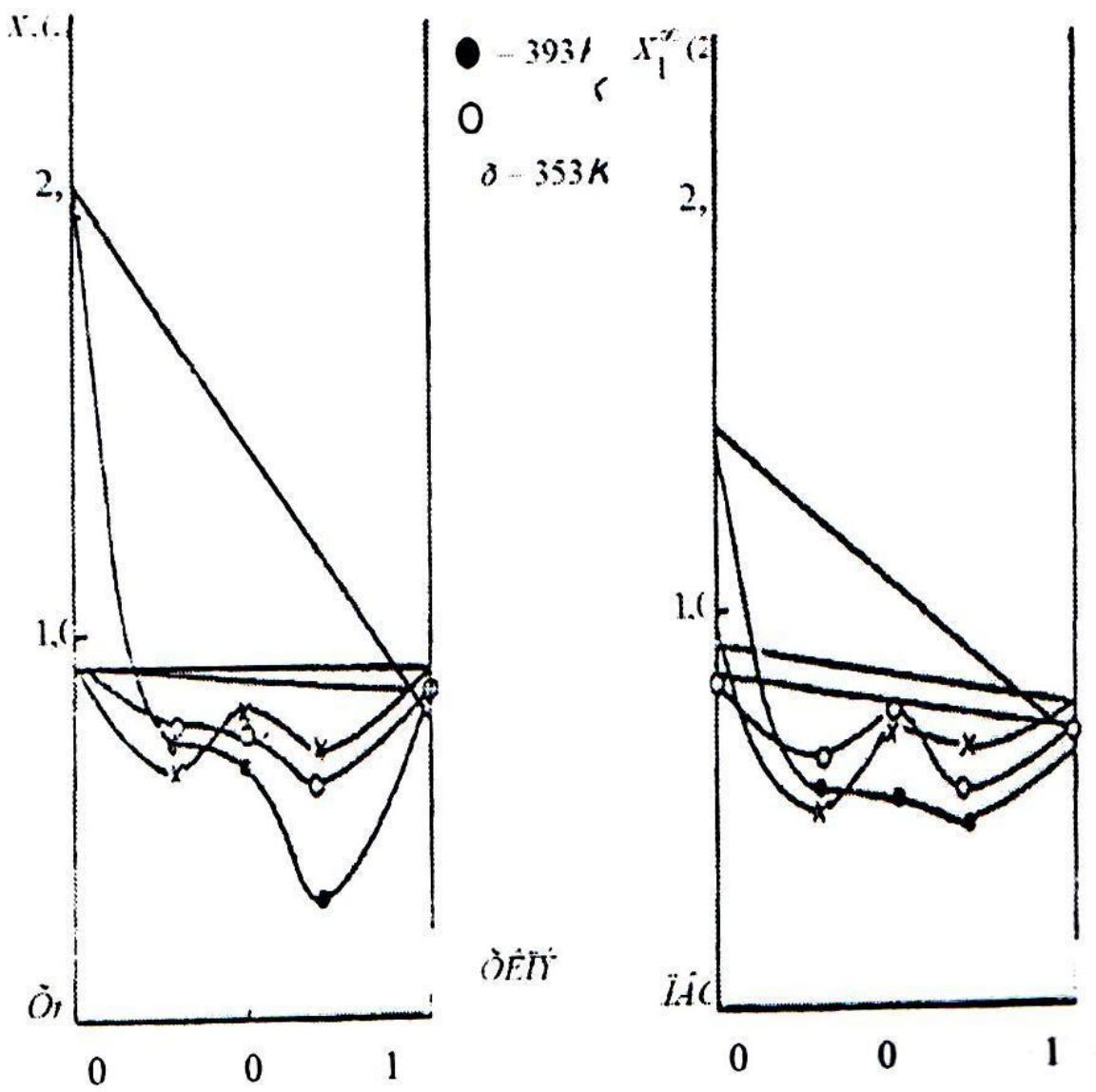

OÉ:

Figure 1. Change of value 1(23) with composition for systems CCPE-CPE-PVC

By little content one of component in mixture the investigation wasn't conducted, because as was indicated in [14] by division of numerator fraction of equation (2) on product $\mathrm{Y}_{2} \cdot \mathrm{Y}_{3}$ by little values $\mathrm{Y}_{2}$ or $\mathrm{Y}_{3}$ the quotient is sharply increased, leading to inequivalent values.

Taking into consideration that value of $X_{23}^{T}$ equal 0.30.4 determine compatibility of the systems from the received experimental data it follows that systems CCPE-CPE and CCPE-PVC are partly compatible.

By experimental received values $V_{g}^{0}$ for sorbates on individual and mixed motionless phases the excess mol mixing energy $G^{\varepsilon}$ of polymers, calculated by equation (3) have been determined.

$$
\left.x_{3} \ln V_{M 3}\right) \quad G^{\varepsilon}=R T\left(\ln V_{M 1}-x_{2} \ln V_{M 2}-\right.
$$

Where $V_{M_{1}}, V_{M_{2}}, V_{M_{3}}$ - a model holding volumes of sorbate by mixture and individual components; $\mathrm{R}, \mathrm{T}$ universal gas constant and absolute temperature. It is expected that for components of mixture with big molecular mass $\Delta G^{\varepsilon}$ ideal - 0 , the average Gibbs energy, related to $1 \mathrm{~g}$ of mixture may be determined by equation (4):

$$
\Delta g_{x}=\frac{G^{\varepsilon}}{M}(4)
$$

Where $\mathrm{M}$ - the average molecular mass of mixed phase.
Having the temperature dependence of quantity $\Delta g_{x}$, a values of enthalpy and entropy have been calculated by equations (5)

$$
\begin{aligned}
\Delta h_{x}=\frac{\partial\left(g^{x} / T\right)}{\partial(1 / T)} \\
=\frac{\Delta h_{x}-\Delta g_{x}}{T}
\end{aligned}
$$

On Figure 2 the concentration dependences of received thermodynamical parameters are shown. As it is evident both investigated systems behave itself in analogous may, but for system CCPE-PVC correlation $\Delta \mathrm{h}_{\mathrm{x}}$ and $\mathrm{T} \Delta \mathrm{S}_{\mathrm{x}}$ is that $\Delta \mathrm{g}_{\mathrm{x}}$ is essentially less by value, than in case of system CCPE-CPE achieving in maximum +0.4 $\mathrm{Joul} / \mathrm{g}$, at the same time as for second system $+1.6 \mathrm{Joul} / \mathrm{g}$, ie. a system CCPE-PVC is more thermodynamically stable than system CCPE-CPE.

By increase of temperature correlation $\Delta \mathrm{h}_{\mathrm{x}}$ and $\mathrm{T} \Delta \mathrm{S}_{\mathrm{x}}$ for different compositions undergo essential changes, moreover observed changings lead to changing of $\Delta g_{x}$ mark. These data testify about that criterion of availability of lower and upper critical temperature (thermodynamical criterion LCTM $-\Delta \mathrm{h}_{\mathrm{x}}<0, \Delta \mathrm{S}<0$ and UCTM $\Delta \mathrm{h}_{\mathrm{x}}>0, \Delta \mathrm{S}>0$ are by appointed composition and temperature for both systems).

Phase diagrams by investigated systems have been calculated by equation spinodaly:

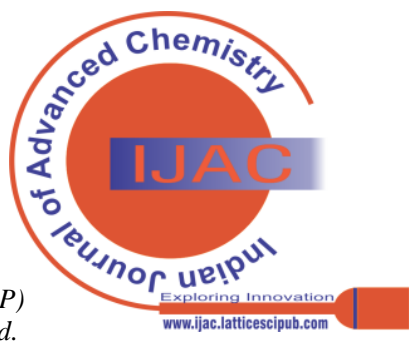


Thermodinamics and Mutual Distribution of Macromolecules in the Systems: Chlorine-Chlorocontaining Polymers

$$
\left(\partial g^{2} / \partial^{2} \omega\right) p=0
$$

By help of the plant (Figure 3) analogous with [18] for determination of thermodynamical parameters of interaction sorbate-polymer or polymer-polymer by us the first derivatives $\Delta \mathrm{g}_{\mathrm{x}}$ by composition, then - the second derivatives by composition have been calculated and graphical dependence $\left(\partial g^{2} / \partial^{2} \omega\right) p \mathrm{p}$ from temperature have been created.
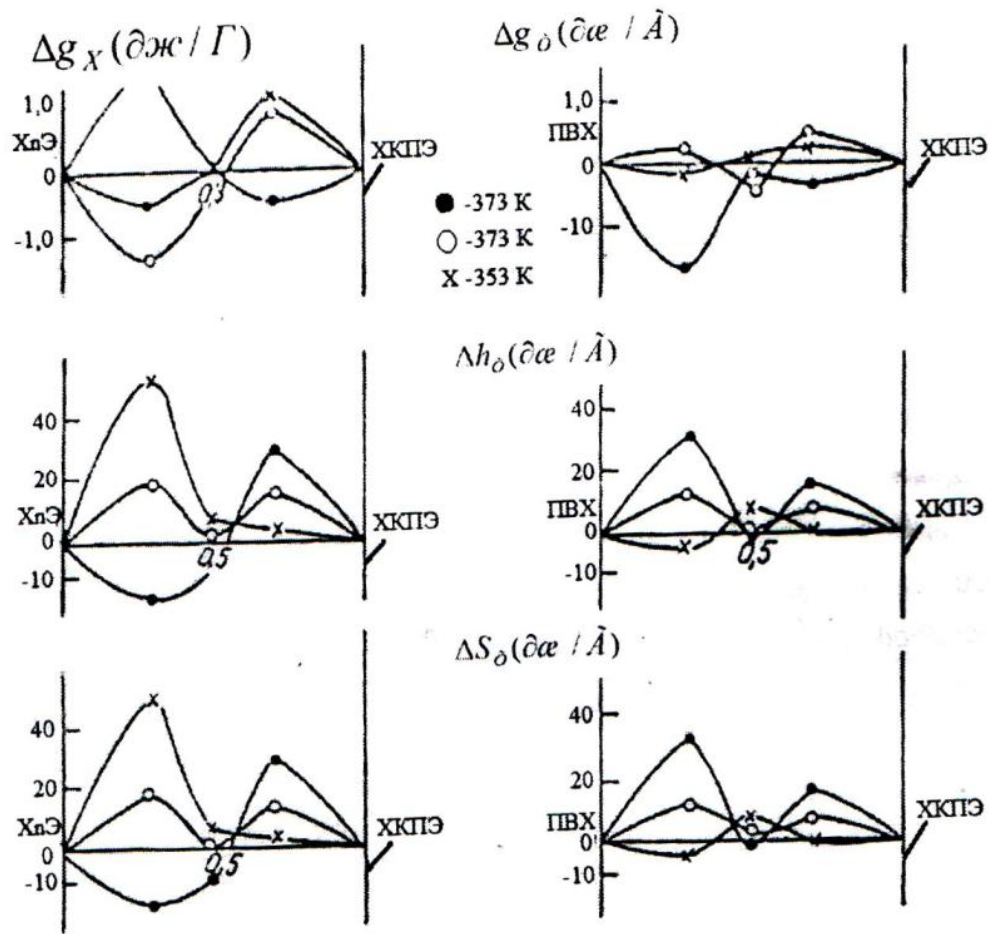

Figure 2. Concentration dependences of thermodynamical parameters in systems CCPE-CPE and CCPEPVC.

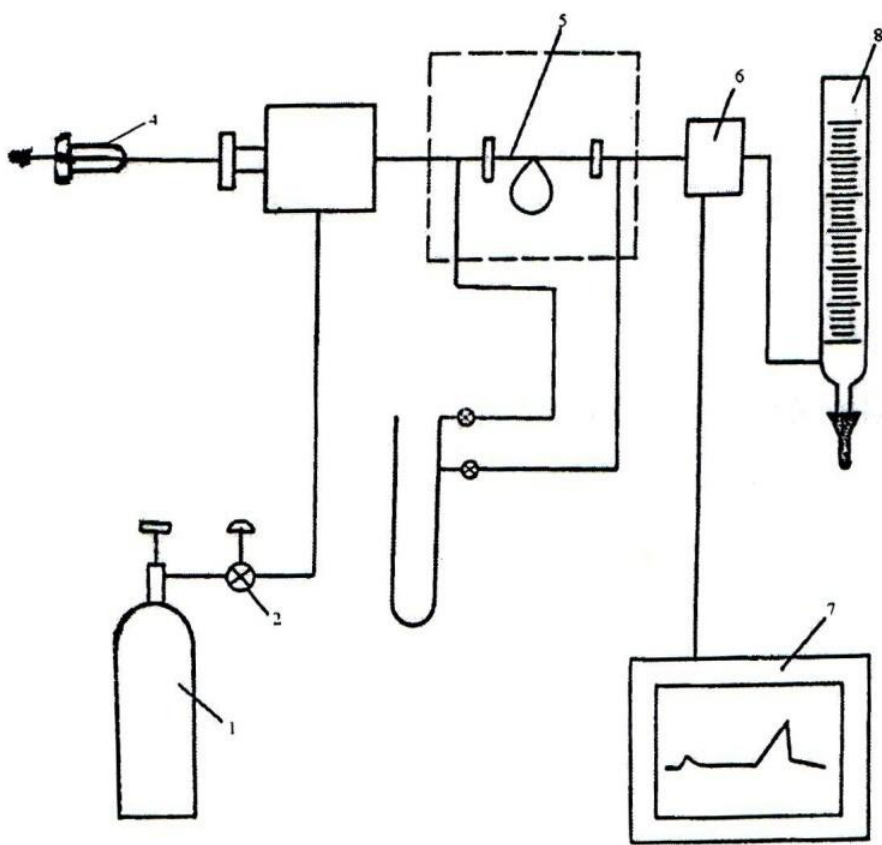

Figure 3. Scheme of plant for determination of thermodynamical parameters of interaction of polymersorbent

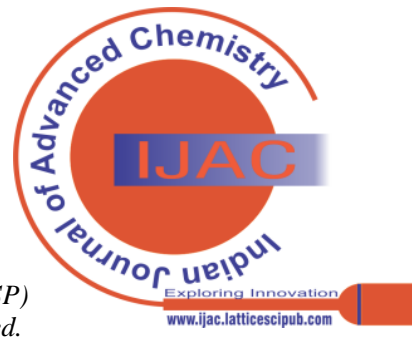


1-container with gas-carrier; 2-regulator of gascarrier pressure; 3-microsyringe for introduction in gas line of sorbate microsamples; 4-evaporator of the block sorbate injection; 5- columns with polymer, piled on carrier, put in thermostate; 6-detector; 7-memory apparatus; 8-soap flowmeter

$\left(\partial g^{2} / \partial^{2} \omega\right) p=0$ the temperatures of phase division have

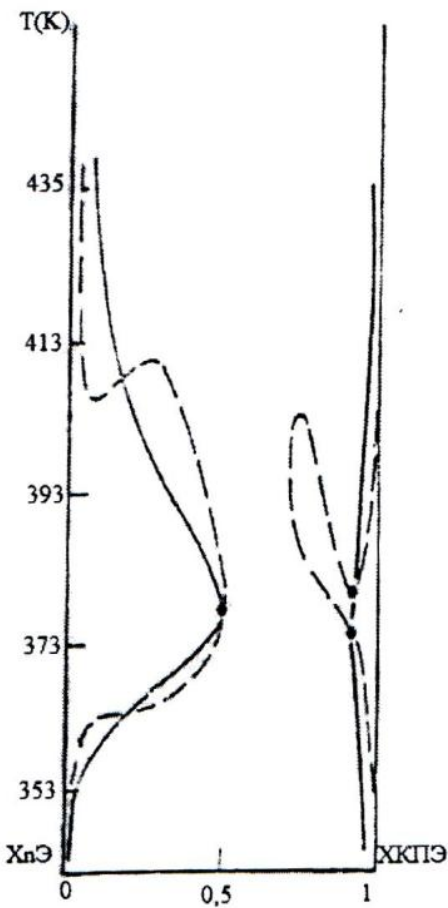

been determined. The received diagrams are shown on Figure4. As it was expected, according to supposition both systems have two critical temperature dissolution - upper and lower. Moreover for system CCPE-PVC the LCTM more than (correspondingly 374 and $366 \mathrm{~K}$ ). This system within critical points is compatible by all composition field.

Figure 4. Diagram of the phase division of temperatures

Asymmetry of the phase diagram as was indicated for example in [13], is characteristic for mixture of polymers with considerable difference in values of molecular mass. Observed bipod stanceis characteristic by polymers with strong polydispersity [14].

\section{CONCLUSIONS}

Analysis of the phase diagram of CCPE-CPE system testify about more the worst compatibility, than in case of CCPE-PVC system . It is interesting to note, that for the first system the UCTM more than LCTM that lead to phase diagram "sand glass" (spinodales become one, giving isthmus) ie. by any temperature it is impossible to get a system being compatible by all field of composition.Compatibility is considerably better by little content of CCPE whereas for system CCPE-PVC compatibility improves by increase of content CPE.

Thus, an experimental comparison of values parameters solubility of polymers, received by two methods: spectra-gas chromatography (SQC) and turbidimetric titration (TDT), characterizing by limit opposite state of polymer by relation to solvent shown the significance difference in parameters solubility for polymers with strong specific interaction between macromolecules, that require attention by use of theory of parameters solubility for supposition of compatibility of polymer pair to method, by which a used value us received. Apparently, that for crystallizing polymers also the same difference in parameters of solubility must observed.

\section{REFERENCES}

1. D.Simonov - Yemelyanov, V.W.Kuznetsov. Principles of compositional materials creation. Text-book. M. MICT, 1987, 85p.

2. Base of technology processing of plastic mass. Text-book for high schools/S.V.Vlasov, M. "Chemistry", 2004, 600p.

3. V.F.Vakhidov, O.M.KArimov, Z.E.Eyvazova. Technics of oil-gas production, Baku, Azerneshr, 2008, 440p.

4. V.K.Krijanovsky, M.A.Kerber, V.V.Burlov. Production of products from polymer materials. Sankt-Petersburg, 2008, 450p.

5. KeremShixaliyev. Propeties of the Composition Based on modified Polyethylenes. International journal of Innovative Technology and Exploring Engineering. Volume-9 issue- / Januaru 2020.pp24842493

Pp / 2484-2293 ISSN-2278-3075, SCOPUS https://www.ijitee.org/download/volume-9-issue-7/ [CrossRef]

6. KeremShixaliyev. Modification of Polymer Wastes and Obtaining Com Composites Based on Them Annotation. International Journal of Innovative Technology and Exploring Engineering (IJITEE). Volume-9 Issue-5, March 2020 [CrossRef]

7. Pp.1072-1076. ISSN: 2278-3075, SCOPUS.Retrievai NumberE2156039520 | 2020 (C) BEIESP https://www.ijitee.org/instructionsfor-authors/

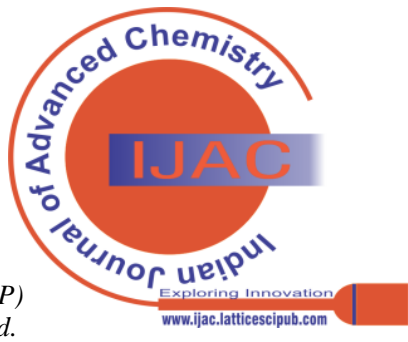


8. AmirovFariz.ShixaliyevKerem. Properties of Linear Low Density Polyethylene. International Journal of Innovative Technology and Exploring Engineering (IJITEE). Volume-9 Issue-9, July 2020.pp. 348-352 ISSN: 2278-3075. SCOPUShttps: //www.ijitee.org/download/volume-9-issue-3/

9. KeremShixaliyev. Paint and Varnish Materials Based on Epoxy Novolacoliqomers Jour of Adv Research in Dynamical \& Control Systems. Vol. 12, Special Issue-02, 2020.pp351-358

10. KeremShixaliyexSefi..DETERMINATION OF COMPATIBILITY OF POLYMER SYSTEMS, SKEP, PU, KhKPE and CHEMICAL FEATURES OF THEIR MIXTURES. Jour of Adv Research in Dynamical \& Control Systems. Vol. 12, Special Issue-02, 2020.pp359-370

11. Ermilova EA, Sizova AA, Ilyicheva NN, Pleshakov DV // Study of thermodynamic compatibility of a three-component mixture of nitramines with a copolymer of methyl methacrylate and methacrylic acid technology / Chemical successes. .-2014 - №2.-p.65-67.

12. Turaev ER, Beknazarov HS, Akhmedov UK, Dzhalilov AT// Interfacial interactions of three-phase polypropylene composite materials./Universum.Technicalsciences./- 2018-№12.-p.57

13. Shastin DA, Wolfson SI, Makarov TV // The impact of modification of triple ethylene propylene rubber on the physical and mechanical properties of rubber./Vestnik of Kazan Technological University.2010-№4.-p.5-7

14. Шыхалиев К. Modification of bitumen with polyethylene and rubber waste .World science Warsaw Poland2018 -№1 (29) 2 C.28 30Zsglolal.poland@ gmail.com

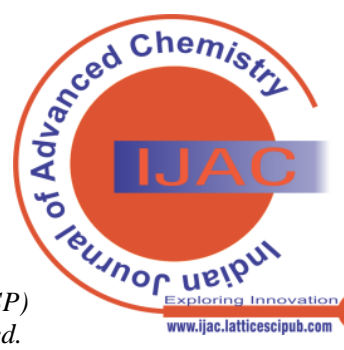

